neither sinks nor floats. The mixture being thus of the same specific gravity as water itself the reading of the hydrometer in it is its error at this degree, and in the case of a wellconstructed and accurately graduated hydrometer this error holds good with only a negligible increase throughout the scale.

Devonshire-street, $\mathbf{w}$.

\section{AN UNUSUAL FOREIGN BODY IN THE FEMALE BLADDER WITH A SIMPLE METHOD OF EXPULSION.}

By A. E. Bullock, M.B., C.M. Edin.

A woman, aged 50 years, came to me on Feb. 17th, 1903, complaining that the day previously in attempting to draw off her urine she had broken the catheter-a very flimsy glass one-and could not recover the missing end. On examination by a sound $I$ at once struck the foreign body and the difficulty that then occurred to me was how to extract it without breakage. Seizing it by a lithotrite or forceps through the dilatied urethra appeared certain to cause fracture. I therefore filled the bladder quite full of fluid by means of an ordinary catheter and syringe and then suddenly dilated the urethra by means of a rectal dilator, introduced, closed, and suddenly opened to its full size. This method was instantly successful, the remains of the glass catheter, which proved to be one and a half inches long and broken off at the second eye, being ejected with great force. The patient made a good recovery without any incontinence of urine.

Leamington Spa.

\section{A}

OF

\section{HOS PITAL PRACTICE, BRITISH AND FOREIGN.}

Nulla autem est alia pro certo noscendi via, nisi quamplurimas et morborum et dissectionum historias, tum aliorum tum proprias Morb.; lib. v., Proœmium.

\section{ROYAL FREE HOSPITAL.}

A CASE OF SPONTANEOUS COMPLETE INVERSION OF THE UTERUS.

(Under the care of Mr. T. P. LEGG.)

For the notes of the case we are indebted to Dr. F. Ivens, late house surgeon.

The patient, aged 25 years, was admitted into the Royal Free Hospital on Sept. 25th, 1902, under the care of Mr. Legg. The patient said that she had been confined one month before admission. Labour lasted 24 hours and the child was delivered by instruments. A few hours after her confinement she became light headed and got out of bed and walked about the room. For three weeks she had a considerable amount of bearing-down pain and blood-stained discharge. The medical man who attended her during her confinement stated that the presentation was normal but that during the second stage the patient became hysterical and the pains ceased. Delivery was then effected by forceps. There was no retention of the placenta and everything appeared to be satisfactory. About four hours after delivery the patient got out of bed, seized her child, and relingui-hed it only after a struggle. On getting her into bed again complete prolapse and inversion of the uterns was found. There were no excessive hæmorrhage and no delirium. The uterus was replaced in the vagina and the patient was kept in bed for three weeks and then taken to the Royal Free Hospital.

With regard to her past history this was the first child and there had been no miscarriages. On admission the patient was very pallid and feeble. Her temperature was $99.8^{\circ} \mathrm{F}$. and her pulse was 100 . The abdomen was flaccid and the linea fusca was well marked. The uterus could not be felt above the pubes. The perineum was torn almost to the anal margin. When the patient strained a smooth red body could be seen at the vulva. On examination the swelling was felt to be pyriform in shape and larger below than above. The surface was covered by odematous mucous membrane, slightly eroded and bleeding readily. On each side at the lower part were two minute orifices corresponding to the Fallopian tubes. Between the neck of the tumour which was formed by the inverted cervix and the vaginal wall was a sulcus about half an inch in depth and external to it was a firm ridge of mucous membrane. The fornices were very deep. Bimanually the fundus could not be felt, though there was some irregularity in the hypogastrium corresponding to the partially invaginated tubes and ovaries. It was clearly a case of complete uterine inversion.

The patient was anæsthetised the same evening after admission and an unsuccessful attempt was made to reinvert the uterus by taxis. The fundus was first squeezed to reduce the congestion and pressure was then made at the orifice of one of the Fallopian tubes while steady counterpressure was maintained abdominally. For three days the patient was kept in bed, the bowels were kept open, and vaginal douches were given, but no reduction in the size of the uterus took place. On Sept. 28th taxis under chloroform was again tried but unsuccessfully. An Aveling's repositor was then inserted but the bands were not fixed very tightly and the patient on recovering from the anæsthetic did not complain of any pain. 24 hours later, as no progress had been made, more pressure was exerted on the inverted fundus by the tightening of the bands of the repositor. In 48 hours the cup of the repositor was inside the cavity of the re-inverted uterus and was removed with some difficulty, a deep cervical tear resulting. The patient progressed well and was discharged on Oct. 17th. The uterus was in good position and had undergone almost complete involution.

Remarks by Dr. IVENS.- - This case appears to have been one of spontaneous inversion caused not by traction on the cord but by relaxation of the uterus while the patient was in the upright position. The absence of shock or excessive hæmorrhage indicates that the process was a more or less gradual one and may hare begun at the placental site. The partially invaginated fundus would then act as a foreign body and excite strong uterine contractions to expel itself. The success following the treatment by Aveling's repositor confirms the almost universal belief that this instrument should be given a fairly prolonged trial before operative measures are considered in similar cases.

\section{KENT COUNTY ASYLUM, MAIDSTONE.}

A CASE OF ACUTE DILATATION OF THE STOMACH ASSOCIATED WITH OPERATION; FATAL TERMINATION.

(Under the care of Dr. Frederick W. Stewart.)

A MALE patient in the Kent County Asylum, Maidstone, aged 55 years, who was a sufferer from epilepsy, complained on Feb. 18th, 1903, of severe pain and tenderness in the perineal region. On examination a hard inflammatory tumour, without apparent fluctuation, was discovered on the right side of the anus and a diagnosis of acute ischio-rectal abscess was readily arrived at. After consultation operation was decided on and in the interim the part was well fomented. The patient was duly "prepared" and on the 20th ether was administered by the senior assistant medical officer of the asylum. Having carefully performed the rectal "toilet" Dr. Stewart made an incision through the brawny tissues and discovered a necrotic focus of about the size of a large bean half an inch from the surface which was easily evacuated by a Volkmann's scoop. There were no "pockets" or fistulous off shoots present. The wound was thoroughly flushed out with carbolic lotion (1 in 20) and packed with alembroth gauze. A suppository of half a grain of morphia and iodoform was next inserted per anum. The usual routine treatment for shock was carried out and the patient recovered in a short time from the effects of the narcosis. No unusual circumstances super ened during the next week, during which the wound was healing satistactorily by granulation. The diet during th $\mathrm{s}$ period consisted of Benger's food and milk and the patient ate well, slept well, and looked well. For a few days there was a slight evening rise of temperature with a morning remission On the fourth day the kowels were relieved by castor oil and afterwards by an occasional glycerine sur pository. On March 3rd-i e, 11 days after the operation-the patient apptared to have a very sharp appetite and thirst which were satisfied ad 
libitum. In the afternoon he became acutely ill and complained of severe pain in the epigastric and umbilical regions. At the same time he vomited a large amount of bile-stained fluid and assumed the decubitus of acute peritonitis. Dr. Stewart's attention having been drawn to a swelling which had been observed suddenly to develop in the area corresponding to the pain, this was examined and percussion was decidedly tympanitic, but this was only obtainable below as far as the midpoint between the umbilicus and the pubes. Above, Traube's space was considerably increased in area. Movements corresponding to peristaltic waves were visible on inspection and splashing sounds could also be easily elicited by the usual method. The pain at this time was extreme and it was with difficulty that the patient could be touched. Owing to his unfavourable reaction to the suppository morphia was contra indicated. Stimulants and frequent injections of strychnine ( $\frac{1}{60}$ th of a grain) were relied upon, as the heart's action was by this time very much embarrassed. A turpentine enema was also ordered, which brought only temporary relief. The frequent passage of a Jacques catheter was necessary owing to the retention of urine which was secreted in fair amount. The abdomen was still increasing enormously in size, this being most marked in the anteroposterior diameter, and within a short time it was extremely tense. Notwithstanding every means adopted to relieve his condition the patient gradually sank and died in great agony on the 5 th.

Necropsy. - At the post-mortem examination, which was held next morning, the stomach was found to be empty and very dilated. Its capacity was $10 \frac{1}{2}$ pints. The walls were extremely thin and pale. There was no evidence of stenosis or stricture anywhere. The first part of the duodenum also seemed to be dilated. The heart was fatty with hypertrophy of the left ventricle, while the right side was dilated and filled with dark thrombi. The kidneys were cirrhotic and cystic. There was a large amount of fatty infiltration throughout the body generally. The bladder was flaccid and much dilated. On dissecting the peritoneum from the rectovesical pouch no trace of deep-seated suppuration could be found and the wound had almost healed. "All the other organs looked healthy.

Remarks by Dr. STEWART. - The comparative rarity in medical literature of recorded cases of acute dilatation of the stomach may perhaps be sufficient justification for bringing the details of the above case under the notice of the readers of THE LANCET. From the foregoing account it would appear that the theory of ordinary septic absorption as a cause of the condition will not easily lend itself as an explanation here. Nor is it reasonable to think, as a factor in its causation, of any toxic effect produced by the anresthetic at the time of operation. 'The condition, however, of "cryptogenetic septicæmia" described by Leube, where no macroscopic appearances could be traced during life or after death, must not be forgotten in elucidation of certain doubtful cases. The simultaneous loss of function in the involuntary musculatures of the stomach and bladder would seem to be due to a paresis either from pathological change or functional incompetence in the sympathetic system. After carefully reviewing all the clinical facts I am led to the belief that the case is a similar one to those few cases described by Fagge as "acute paralytic distension" and I think that it should be relegated to this category. It follows, then, that the association with operation may be looked upon purely as an accidental coincidence. For permission to publish the case I am indebted to Dr. F. Pritchard Davies, the superintendent of the asylum.

AT a meeting of the Northern and Midland Division of the Medico-Psycholngical Association, held at Cheddleton Asylum, Leek, on April 30th, Dr. Menzies being in the chair, Dr. E. F. Trevelyan of Leeds exhibited a number of "dry brain" preparations and read a paper on the method of preparing them. He expressed preference for Laskowsky's method. Although there was general s hrinkage the convolutions of the brain were not distorted by this method and the colour was well maintained. For demonstration purposes brains prepared in this way were of great value; they could be freely handled, they were elastic and tough, but did not become hard. Dr. Rice showed a remarkably large specimen of an aneurysm of the middle cerebral artery and gave an interesting description of the clinical features of the case.

\section{Stledical Sorcieties.}

\section{PATHOLOGICAL SOCIETY OF LONDON.}

Hypochlorous Acid as a Disinfectant.-Cretinismin Calves.Bacteriological Examination of a Case of so-called Rheumatoid Arthritis. - A Note on the Relative Readings given by the Hamoylobinometers of Fleischl and Haldane. - Renal Dropsy.

A LABORATORY meeting of this society swas held on May 5th, Sir John BuRdon Sanderson, the President, being in the chair.

Dr. F. W. ANDREwEs and Dr. K. J. P. ORTON made a preliminary communication on Hypochlorous Acid as a Disinfectant.

Dr. C. G. Seligmann read a paper on Congenital Cretinism in Calves. He said that in every herd of Dexter Kerry cattle which had been under observation in this country it had been noted that a considerable number of monsters, showing a constant type of deformity, were born. These were, in fact, cretins and the interest of this lay in the facts (1) that they were practically limited to the breed mentioned; (2) that the condition arose in foetal life; and (3) that it was associated with a diseased condition of the placenta in the parent cow. Of 82 calves born in two herds 19 were monsters of the type under consideration and showed the characteristic short basis cranii, very short limbs, fat pads, \&c. The thyroids of all such calves examined showed absence of colloid and the usually malformed or ill-developed vesicles of the gland were choked with more or less spheroidal cells. Extracts of these thyroids when injected intravenously caused no fall of blood pressure. Clinically the pregnancy of a cow about to produce a cretin showed marked deviation from the normal and in the placentæ examined there was extreme myxomatous and œdematous change affecting many of the cotyledons.Dr. ANDREwes suggested that the condition present in these calves was closely allied to the abnormality known as achondroplasia met with in the human fœtus. He had, however, examined the thyroid gland in cases of this disease and had never been able to discover any abnormality such as had been found in the calves described by Dr. Seligmann.-Mr. S. G. SнаттосK said that he considered the calves described by Dr. Seligmann were true cretins and resembled exactly the condition produced by the removal of the thyroid gland in young animals. If the thyroid gland was removed in the pregnant bitch the bitch underwent no cretinoid changes, but it was found that the thyroid gland of the foetus became hypertrophied and assumed the function of the maternal thyroid gland. It was difficult to see why a healthy mother should give birth to a cretinoid fœtus when the function of the thyroid gland could be vicariously supplied by the maternal thyroid gland. Two explanations might be offered firstly, that the disease of the placenta prevented vicarious interchange between mother and fcetus; and secondly, that the herd of cattle which produced these abnormal fotuses were themselves in a sub-cretinoid condition.-Dr. H. Morley FLETCHER asked if a cow which had thrown a cretinoid foetus would at a following pregnancy again produce a cretinoid calf. He also asked if the thymus gland had been noticed to be large in these calves.-Dr. SEIIGMANN, in reply, said that although the condition of the calves might in many respects resemble achondroplasia, yet the absence of colloid substance from the thyroid gland seemed greatly in favour of the view that they were cretinoid. He did not think that there was any evidence to show that the herd of cattle were in a subcretinoid condition. A cow which had thrown a cretinoid foetus might on a subsequent preguancy bear a perfectly healthy calf. There was no noticeable enlargement of the thymus gland.

Mr. G. E. GAsK read a paper on the Bacteriological Examination of a case of Acute Rheumatoid Arthritis. He said that a woman, aged 29 years, in January, 1903, was delivered of her second child, the labour being apparently normal and not followed by fever. A few days later the right knee-joint became hot, red, and swollen. Subsequently many joints became similarly affected, the patient being confined to bed. The appearance of the patient was one of 